\title{
Estrategias de visibilización y procesos de identi- ficación boliviana en la prensa gráfica y en la red social Facebook, en dos ciudades del centro de la provincia de Buenos Aires, Argentina
}

\author{
Mercedes Mariano \\ CONICET - PATRIMONIA-INCUAPA - FACSO - UNICEN \\ mercedes.mariano@gmail.com \\ María Eugenia CONFORTI \\ CONICET - PATRIMONIA-INCUAPA - FACSO - UNICEN \\ meconfor@soc.unicen.edu.ar \\ María Vanesa Giacomasso \\ CONICET - INCUAPA - FACSO - UNICEN \\ vanegiaco05@gmail.com \\ María Luz ENDERE \\ CONICET - PATRIMONIA-INCUAPA - FACSO - UNICEN \\ menedere@soc.unicen.edu.ar
}

Recibido: 5 de octubre de 2013

Aceptado: 26 de marzo de 2015

\section{RESUMEN}

Los usos y las formas de identificación intra y extra grupo a través de los medios de comunicación son aspectos escasamente explorados en los estudios sobre las identidades en ciudades de tipo intermedias del centro de la provincia de Buenos Aires, Argentina. Por ello, el objetivo de este trabajo consiste en analizar y discutir los modos en que se visibilizan y construyen las representaciones y manifestaciones de los inmigrantes y descendientes bolivianos, específicamente en la red social Facebook y en la prensa gráfica local de las ciudades de Olavarría y Azul. Se pretende contribuir a la comprensión de la manera en que se producen los diversos discursos y saberes de estos grupos, así como identificar a estos medios de comunicación como instrumentos que posibilitan intervenir desde otros espacios de reconocimiento y legitimidad.

Palabras clave: Medios de comunicación, identidades bolivianas, discursos y representaciones.

\section{Bolivian Visibility Strategies and Identification Processes in Print Media and Social Networks in Two Cities in the Center of Buenos Aires Province, Argentina}

\section{ABSTRACT}

The uses and forms of intra and extra-group identification through the media are aspects poorly explored through identity studies related to intermediate type cities such as those of located at the center of the province of Buenos Aires, Argentina. Therefore, the aim of this paper is to analyze and discuss the ways that representations and manifestations of Bolivian immigrants and descendants become visible and are constructed, specifically through the social network Facebook and local print media in the cities of Olavarría and Azul. It aims to contribute to the understanding of how the various discourses and knowledge of these groups occur and to identify the role of these media as means that enable intervene from other areas of recognition and legitimacy.

Key words: Mass media, Bolivian identities, discourses and representations.

Sumario: 1. Introducción. 2 Antecedentes. 3. Manifestaciones bolivianas en Olavarría y Azul. 4. Manifestaciones bolivianas en la prensa gráfica. 5. El caso de Olavarría. 6. El caso de Azul. 7. Manifestaciones bolivianas en la red social Facebook. 8. Comentarios finales. 9. Referencias bibliográficas. 


\section{Introducción}

En el centro de la provincia de Buenos Aires, específicamente en las ciudades de Olavarría y Azul ${ }^{1}$, existen agrupaciones de inmigrantes bolivianos de variada procedencia y con diverso grado de organización, que presentan particularidades y matices en el proceso de construcción de sus identidades. Como muchos otros grupos de inmigrantes en el país, ellos poseen un calendario festivo propio, se integran, además, con sus danzas y rituales a las festividades locales, evocan sus tradiciones y costumbres y construyen así nuevos espacios de expresión en los que manifiestan símbolos transnacionales y significados sociales profundos (Mariano 2011, 2015).

El estudio de la inmigración boliviana en Argentina ha sido abordado desde distintos enfoques teóricos. Sin embargo, es posible observar que son escasos los trabajos que articulan las estrategias de identificación y visibilización bolivianas en los espacios que posibilitan las tecnologías de la información y la comunicación y su relación con las representaciones que se construyen desde ellos.

En este contexto se considera que a través del estudio de las fuentes periodísticas es posible analizar las imágenes y discursos que se construyen y comunican socialmente «desde afuera» del propio grupo de inmigrantes y descendientes. Este análisis es relevante en tanto permite comprender cuestiones tales como las formas en que se anuncia una celebraciones particular, así como la manera en que son vistos los grupos en cuestión, los discursos sociales que se expresan acerca de ellos, los aspectos que se puntualizan cuando los periodistas describen sus prácticas culturales; así como el léxico que utilizan, la información que consignan y la que desconocen u omiten mencionar, entre otras.

Por su parte, las «nuevas» fuentes de información y sociabilidad que se han desarrollado mediante el uso de las tecnologías de la información (como Internet), han revolucionado las formas tradicionales de comunicación posibilitando el encuentro con realidades inéditas. En términos de procesos de identificaciones sociales, no se puede dejar de conocer y acceder a la información que se encuentra en el universo de las redes sociales, como Facebook, donde se conforman grupos de afinidades diversas (Boggi 2011) que se expresan «desde adentro» a partir de su propias voces. Metodológicamente, el análisis de este tipo de información representa un desafío que enriquece la investigación antropológica y comunicacional ya que pone en escena otros procesos de auto-identificación.

En suma, el objetivo principal de este trabajo es identificar cómo se construyen, visibilizan y comunican las representaciones que refieren a las identidades bolivianas en la región centro de la provincia de Buenos Aires, a partir del análisis de los discursos que aparecen tanto en la prensa local como en la red social Facebook. Se espera entonces poner en relación y comparación las formas de identificación intra y extra grupo, intentando establecer conclusiones que complejicen y profundicen aspectos hasta el momento escasamente explorados.

\footnotetext{
1 La ciudad de Olavarría es la cabecera del partido del mismo nombre - unidad política territorial- que posee una superficie de $7.715 \mathrm{~km}^{2}$, está ubicado en el centro geográfico de la provincia de Buenos Aires y tiene una población de 111.000 habitantes. La ciudad de Azul es la cabecera del partido del mismo nombre, limítrofe a Olavarría, su extensión es de $6.615 \mathrm{~km}^{2}$ y tiene 55.728 habitantes.
} 


\section{Antecedentes}

El estudio de la inmigración boliviana en Argentina ha sido abordado por investigadores de distintas formaciones y desde diferentes perspectivas. De hecho, los procesos migratorios se convirtieron en el eje de muchas investigaciones en diversos campos, a saber: la geografía cultural, con autores como Sassone y De Marco (1991) Sassone (1994, 2007, 2009); la sociología, con Zalles Cueto (2002), Benencia (1997, 2008, 2009a, 2009b) y Caggiano (2005) y la antropología, con exponentes como Giorgis (2004), Grimson (2000) Laumonier (1990), Balán (1990) García Vázquez (2005), entre otros. La mayoría de estos autores realizaron estudios tendientes a separar en etapas los procesos migratorios $\mathrm{y}$, en general, propusieron que los desplazamientos de poblaciones desde Bolivia tienen una larga historia y son de gran relevancia para ese país. Estas investigaciones no se detienen, sin embargo, en una simple cronología de eventos migratorios, sino que indagan, además, en las razones que los generaron. Es decir, intentan dar cuenta de por qué, en determinado momento, se generó un gran movimiento de poblaciones desde Bolivia y qué condiciones socio-económicas se están dando en Argentina para convertirse en un posible punto de llegada de los grupos que emigran.

Las redes sociales y familiares, que tuvieron un rol clave en los ciclos migratorios de bolivianos a Argentina, fueron también el eje de muchas investigaciones (ver Benencia 1997; Ludger 2002; Sassone 2007, entre otros). En ellas se analizan cómo los agentes sociales promueven una estructura de relaciones que delinean las formas de flujo humano y cómo los grupos y los individuos se apropian del nuevo ambiente social y espacial, dando lugar a un verdadero sistema de reproducción cultural que a la vez se convierte en canal y base para el traslado de nuevos inmigrantes.

En esta misma línea de trabajo, autores como Loumonier, Rocca y Smolensky (1983) Grimson (1997, 2000, 2005), Zalles Cueto (2002) Giorgis (2004) Gavazzo (2005) Caggiano (2005) han demostrado cómo a medida que los migrantes se fueron asentando en las grandes ciudades argentinas, comenzaron a desarrollar diversas estrategias para adquirir trabajo, vivienda, documentación, y construir lugares donde juntarse, manifestando prácticas de identificación en el nuevo contexto urbano. En este sentido, en las ciudades existen múltiples ámbitos de producción y reconstrucción de identidades vinculados a la «colectividad boliviana». Se trataría, en términos de Grimson (2000), de un «tejido social diverso» y disperso por distintas zonas que incluye «bailantas», restaurantes, fiestas familiares y barriales, ligas de fútbol, programas de radio, asociaciones civiles, publicaciones, ferias y comercios de diferente clase, que dan cuenta de múltiples espacios vinculados a la «bolivianidad». Estos procesos de re-territorialización estarían mostrando, para este autor, la necesidad de los grupos inmigrantes de reunirse y comunicarse frente a un entorno desconocido $\mathrm{y}$, muchas veces, hostil. Este entramado parece constituir otro mundo, diferente de la ciudad mayoritaria y las propias ciudades bolivianas y que, sin embargo, vive y crece en permanente relación con ambas (Grimson 2000).

En suma, como lo expresa Zalles Cueto (2002), los ejemplos de la existencia de una colectividad cohesionada (aunque no por ello homogénea) boliviana en Argentina son muchos: la conformación de barrios como los de Lugano o Charrúa en Buenos 
Aires; las ferias comerciales que reproducen el paisaje de los mercados bolivianos, ya sea en el Gran Buenos Aires o en las provincias norteñas de Salta o Jujuy; el desarrollo de órganos de prensa y de radio, como Urkupiña, que incluye programas en idioma aymara; la celebración de fiestas religiosas y patronales relacionadas con el lugar de procedencia.

En relación con las investigaciones que vinculan a los grupos de inmigrantes y descendientes bolivianos con los procesos de comunicación, se han realizado algunas que merecen mencionarse. El trabajo de Sergio Caggiano (2005) se constituye en un antecedente clave en este sentido. En el se propone una perspectiva teórico metodológica para su abordaje, que está ligada a una concepción de las identificaciones sociales que busca considerar tanto la autoidentificación como la heterodefinición de los inmigrantes bolivianos. Además analiza los procesos de construcción de sentidos desde la perspectiva de la comunicación intercultural por medio del análisis sobre el discurso de la prensa local, tomando como caso de estudio las imágenes que la sociedad de La Plata (capital de la provincia de Buenos Aires) construye acerca de los inmigrantes bolivianos. Su finalidad es reconstruir las diversas imágenes configuradas en un conjunto general de discursos sociales. Esto le permitió poner de relieve las particularidades de cada proceso y los modos en que toman forma las relaciones interculturales y las configuraciones identitarias.

Desde la producción de textos de los propios inmigrantes y descendientes, Grimson $(1997,2005)$ analiza los procesos comunicativos de identificación boliviana en los relatos construidos en el video y en la radio en la ciudad de Buenos Aires para identificar el diálogo que esta colectividad instituye con los «otros». En estos trabajos, el autor describe cómo estos dos espacios de comunicación ponen en circulación mercancías identificadas con la bolivianidad y constituyen un puente a través del cual establecer conversaciones con la «sociedad receptora» y construir nuevas propuestas de inserción social.

Cabe destacar que las dos investigaciones mencionadas estudian estos procesos en grandes ciudades, por lo que cabría preguntarse cuáles son los discursos y las representaciones que se construyen desde la prensa en torno de «las colectividades bolivianas» en ciudades de tipo intermedias, como las de Olavarría y Azul y, además indagar acerca de cuáles son los textos que los propios grupos generan y ponen de manifiesto en dispositivos mediáticos y redes sociales como Facebook.

\section{Manifestaciones bolivianas en Olavarría y Azul}

A través del trabajo de campo llevado a cabo entre los años 2009 y 2013 (Mariano 2014) $)^{2}$ pudo contextualizarse la llegada de los inmigrantes bolivianos a las ciudades de Olavarría y Azul entre las décadas de 1930 y 1980. En los dos casos fue posible advertir que dichas ciudades no fueron los destinos directos de los primeros inmigrantes, sino que su llegada se produjo después de haber estado trabajando en otras y

2 Se trata de una tesis doctoral inédita. Pueden consultarse resultados parciales publicados en Mariano 2011 y 2015. 
que la mayoría de ellos llegaron a finales de la década de 1950. Es decir que dentro de sus proyectos iniciales, estas ciudades no fueron destinos prioritarios, aunque finalmente, para la mayoría, se convirtieron en los destinos definitivos (ver Mariano 2015).

Por ello es posible encontrar en la actualidad, agrupaciones compuestas de al menos tres generaciones y con diversos grados de organización. En Olavarría existe una Asociación de Residentes Bolivianos (ARBO) constituida formalmente desde hace más 25 años, a través de los cuales esta «comunidad» fue creciendo en organización, consolidación, visibilización y reconocimiento. En la actualidad coexisten cuatro generaciones, entre inmigrantes y descendientes (y quienes se adscriben étnicamente como tales), que llevan a cabo manifestaciones culturales bolivianas en la ciudad. La más representativa se desarrolla cada fin de semana próximo al 5 y 6 de agosto, fecha en la cual irrumpe en la cotidianeidad de la ciudad una celebración con características religiosas, festivas y patrias a la vez: la fiesta de la Virgen de Copacabana. Esta celebración es convocada el mismo día que se conmemora la Independencia boliviana (6 de agosto) lo que fortalece el núcleo convocante y hace posible un juego de imágenes que podría responder a la heterodefinición de los «no bolivianos», y a reforzar «la identidad boliviana» como un todo en el contexto migratorio (Mariano 2011). Para dicho evento, dos barrios se adornan con banderas, arcos, estandartes y pueden observarse automóviles con cargamentos y símbolos representativos de la cultura boliviana. En varias calles se extiende una procesión que sigue un recorrido previamente demarcado. La celebración posee una matriz original de sentidos, anclada en tradiciones, en un pasado común y en una identidad colectiva a la cual «contribuyen a dar forma y sustento múltiples, simultáneas y cruzadas referencias» (Rotman 2004: 145). En este contexto puede observarse la existencia de diversos grupos de danzas como los Tinkus, los Caporales, los «negritos» y una fraternidad cueca. Esta diversidad funcionaría como un modo de diferenciación al interior de la colectividad, y como una variante cultural que enriquecería el imaginario de los «no bolivianos» con otros universos simbólicos, constituidos por las expresiones bolivianas.

Esta fiesta se constituye en una expresión de su condición de migrantes y en una instancia «ideal» a la luz de la cual identificar los modos por los cuales estos grupos reflexionan y debaten su bolivianidad (Giorgis 2004: 114). Esta manifestación y las diversas representaciones que en ella circulan son comprendidas como estrategias activadas por los actores que buscan mantener actualizado un patrimonio cultural inmaterial con el cual identificarse y visibilizarse. Funcionaría, a su vez, como un medio para construir un legado lo suficientemente consolidado como para ser transmitido a las generaciones siguientes y resignificado a través del tiempo (Mariano 2011).

En la ciudad de Azul, el proceso fue diferente. Se pudieron identificar dos generaciones, una compuesta por los primeros inmigrantes, de los cuales ya no quedan representantes y otra formada por sus descendientes directos. En este contexto cobra importancia un tercer grupo constituido por jóvenes de edad escolar que, si bien no son descendientes directos de bolivianos, desde el 2011 se están involucrando con la «comunidad» y participando en sus manifestaciones culturales. El espacio que habitan y con el que se identifican los informantes en Azul, se imprime con características negativas en el imaginario de los sectores hegemónicos de la ciudad. Se trata de un 
barrio marginado, y es en la periferia desde donde se fue conformando un movimiento de reivindicación social y colectiva que utilizó como vehículo para su reconocimiento una comparsa que representa danzas bolivianas: Reina Mora. Las protagonistas, son mujeres descendientes de una familia de inmigrantes que comenzaron a organizar a los más pequeños del barrio (aún aquellos sin nexos con la bolivianidad), que se manifestaban en las calles a través de la percusión de tarros y tambores. Se trata de un movimiento relativamente nuevo y emergente que no evidencia conflictos internos o intereses divergentes, y cuyo objetivo principal es combatir la discriminación social por medio de la visibilización de «otra» diversidad cultural, promoviendo, a su vez, el respeto por lo distinto.

La confección de trajes y máscaras, así como el tiempo compartido en los ensayos, favoreció su consolidación como grupo. El objetivo del trabajo conjunto fue generar la misma indumentaria para que todos pudieran sentirse iguales y protagonistas. Su reconocimiento se produjo luego de participar en 2011 en los carnavales locales y desplegar un conjunto de elementos visuales y expresivos que incidieron en la obtención del primer premio por más de dos años consecutivos. Sin embargo, el mayor logro se alcanzó en el plano social por la visibilización y el reconocimiento obtenido en la ciudad y en el municipio. En la actualidad tanto Reina Mora como el barrio donde habitan sus integrantes han dejado de ser vistos como marginales, para transformarse en portadores de elementos culturales de identificación colectiva, que se activan en el presente y comienzan a ocupar un lugar central en espacios de los cuales antes no participaban ni tenían cabida. El reconocimiento por la comunidad en general y por el gobierno local en particular, propició nuevas instancias para la puesta en valor de «lo boliviano». Por todo ello puede afirmarse que Reina Mora es una construcción social gestionada «desde abajo» y de manera participativa por personas que utilizan «su diferencia», o al menos algunos aspectos característicos de ella, como herramienta para luchar contra los prejuicios sociales.

\section{Manifestaciones bolivianas en la prensa gráfica}

En este contexto, resulta interesante analizar lo que la prensa gráfica comunica, no sólo porque esto permite comprender cómo los medios producen discursos y construyen realidades, sino también para conocer el alcance y la circulación de esos discursos en un lugar determinado, y cómo estos se articulan con los imaginarios sociales. Probablemente constituya una obviedad afirmar que el relevamiento de la prensa local no representa la totalidad de las visiones que se construyen en torno de la «colectividad de bolivianos» en Olavarría y Azul. Sin embargo, aunque escaso y arbitrario, el recorte permite mostrar otra dimensión, que es necesaria para comprender y problematizar la manera en la que los discursos se entrecruzan e interactúan, creando imágenes y representaciones acerca de «lo boliviano» en estas ciudades. Por ello, se parte del análisis de los diarios como dispositivos de producción de sentido (Verón 2001) y en términos de espacios de educación no formal (sensu La Belle 1980; Sarramona 1992), en consideración a su capacidad para instalar diversos temas y dotarlos de relevancia, así como para constituirse en un referente al que el público accede no 
sólo para informarse sino, además, para apropiarse de conocimientos que le permiten construir una visión de su entorno (Conforti 2012). Debe tenerse en cuenta además que la mayoría de los conocimientos que las personas poseen acerca de las cuestiones públicas no provienen de la experiencia personal directa sino de los medios que funcionan como principal fuente de información (McCombs 2004).

\section{El caso de Olavarría}

En la última década, los diarios han dado cuenta de la celebración que se realiza en Olavarría en honor a La Virgen de Copacabana y en conmemoración a la independencia boliviana. Para analizar el impacto de las notas periodísticas (constituidas por artículos y gacetillas de prensa), que incluyen entrevistas y fotografías, se llevó a cabo un análisis de tipo cualitativo de las noticias publicadas por dos diarios $-E l$ Popular e Infoeme- durante los años 2008; 2009; 2010; 2011 y 2012. La elección de estos dos diarios se basó en que El Popular es el único periódico de versión impresa y de venta diaria con cierto alcance regional y con una tirada promedio de 6.000 ejemplares durante los días de semana y de 11.500 los días domingos (ver Conforti 2012). Por su parte, Infoeme es el diario online más consumido y visitado en la ciudad, con una corta trayectoria histórica (surge en septiembre de 2006), pero con un promedio de 19.000 visitas por día.

Si bien a través de la búsqueda y lectura de estas fuentes es posible encontrar diversas noticias que tienen a estos actores sociales como co-protagonista (a saber, festejos por el día del inmigrante, el carnaval, etc.) el análisis se circunscribirá a aquellas que refieren a la celebración del mes de agosto.

$\mathrm{Al}$ analizar la información que transmite cada uno de estos dos diarios, se observa una diferencia en relación al tratamiento de la celebración. El que publica noticias online tiende a apelar al aniversario de la independencia boliviana en más del $70 \%$ de los títulos. La ausencia, en la mayoría de ellos, de la mención de «la fiesta patronal» parece indicar que las connotaciones festivas y religiosas pasan a ser un «aditamento» secundario, ligado a la celebración patria. Por ejemplo, algunos títulos señalan: «Comenzaron las actividades por el aniversario de la Independencia de Bolivia» (Infoeme, 10 de agosto de 2008); «ARBO: festejos de Independencia y apuesta a la integración» (Infoeme, 9 de agosto de 2009); «Se organizan los festejos del 185 aniversario de la Independencia de Bolivia» (Infoeme, 3 de agosto de 2010); «Festejos por el 186 aniversario de la Independencia de Bolivia (Infoeme, 4 de agosto de 2010). Recién en la segunda publicación del 2011, un título anunció: «La comunidad boliviana celebra la Independencia y la fiesta Patronal» (Infoeme, 7 de agosto de 2011). De modo similar, en el 2012 se publicó el siguiente título: «Fiesta de Virgen de Copacabana e Independencia de Bolivia» (Infoeme, agosto de 2012).

Todas las notas periodísticas de este diario online tienen imágenes actuales. En el $100 \%$ de ellas se desarrolla por completo la programación de las diferentes actividades a llevarse a cabo durante los dos días. Se hace también una breve mención al acto protocolar y se brinda la información para que el lector sepa en qué lugar y a qué hora se efectúan las diversas manifestaciones. 
En el caso de El Popular, se analizaron también 2 noticias de este tipo, que se limitan a comunicar la hora y el lugar de todas las actividades. En su mayoría, estas se publicaron los días previos al fin de semana en que se llevó a cabo la celebración. Sin embargo, lo que diferencia la cobertura de este tema con respecto al diario anterior son las notas que se publicaron durante los días en que se desarrolló la fiesta. Se pudieron encontrar, al menos, tres notas por año durante el 2010, el 2011 y el 2012. La cantidad de publicaciones anuales se reduce hacia atrás en el tiempo. El contenido difiere respecto a Infoeme, por la forma de presentarla. Se observa que paulatinamente comienza a haber un acercamiento de los periodistas a las personas que desempeñan distintos roles en la organización de la fiesta y, por ello, es posible observar cómo se entremezclan en las noticias, las voces de los protagonistas. En estos casos, no se trata solo de nombrar, anunciar y describir actividades, sino también de comprender parte de la historia y de las significaciones en juego.

A través de este tipo de notas, es posible identificar el crecimiento de una celebración que es reconocida como religiosa y patria a la vez. Algunos de los titulares fueron: «Entre el aniversario de la Independencia y la devoción a la Virgen de Copacabana. La fiesta de Bolivia en Olavarría» (Título de El Popular 2008); «Colorida fiesta Boliviana en Olavarría» (El Popular 8 de agosto de 2010); «Sentida Celebración Boliviana» (El Popular 9 de agosto de 2010); «Fiesta de la Virgen de Copacabana» (12 de agosto de 2012). Para desarrollar el análisis de estas notas más extensas, se identificaronn los modos en que son caracterizados por la prensa, tanto la ceremonia festiva como «la colectividad».

En el análisis del discurso escrito, los términos «origen», «distancia», «transmisión», «tradición», «color», «brillo», «movimiento» y «devoción» parecen ser los términos más usados para identificar y caracterizar la ceremonia festiva. Se pueden encontrar breves párrafos que aluden al surgimiento de esta ceremonia en Bolivia y las relaciones y diferencias con la que se lleva a cabo en la ciudad de Olavarría (El Popular 2011). El propósito de la fiesta se explica en términos de «acortar distancias». No parece ser un desafío el hecho de transmitir a las generaciones venideras esta tradición. El contexto hace posible un evento «colorido» lleno de «movimiento y brillo» que permitiría, además, en palabras de la presidenta de la Colectividad, «otro modo de relacionarse con la ciudad» actual (El Popular 2010).

En suma, la fiesta es caracterizada en este medio como una celebración que es, a la vez, vistosa y sentida. Es el espacio donde se ponen en escena danzas y grupos de baile típicos, «costumbres del altiplano» y platos tradicionales. Hay un intento por narrar, y por ende, darle a conocer al lector el significado de determinados elementos y actividades presentes en la ceremonia que son significativas para la «comunidad». Ejemplo de ello es la referencia al rol y la definición de los pasantes, el uso del aguayo y la hoja de coca y el acto que los lleva a rociar las imágenes de La Virgen con cerveza, entre otros (El Popular 2011). Se dedican también espacios considerables a los testimonios de las personas mayores que organizan estas manifestaciones y que explican, en sus propios términos, las razones por las cuales estas prácticas y manifestaciones emergen y perduran en la ciudad de Olavarría, por ejemplo: «Para nosotros esta celebración es muy importante y sentida... el propósito es el de mantener y 
transmitir nuestra cultura originaria... estos días provocan nostalgia, se extraña» (El Popular 2008).

Para ello se evoca la memoria de sus protagonistas, se apela a reconstruir fragmentos de sus historias y trayectorias migratorias que le den sentido a esta celebración. En este contexto, surgen términos como el de «pobreza», «migración», «Virgen», «sede social», «trabajo»y «unión», para dar cuenta de una «colectividad» que crece a través del tiempo y que se encontraría, en sus palabras, «más unida que nunca».

Los conceptos más usados para definir a la «colectividad» se repiten para caracterizar la celebración: el color, la música y la devoción se convierten en el denominador común de la crónica periodística para hacer alusión a estos grupos.

Cuando se hace referencia a las celebraciones bolivianas en estos medios de prensa, se utilizan términos que parecieran describir un evento equilibrado, armónico, ausente de conflictos y que tendría un único sentido, el de perpetuar la tradición a través de las generaciones; ya sea celebrando los 187 años de la Independencia o reivindicando los símbolos religiosos. Lejos del análisis quedan las significaciones múltiples, diversas y propias de cada grupo, que podrían ponerse de manifiesto si se escucharan las voces de las generaciones más jóvenes.

Se apela a «las raíces intactas» (Subtitulo de un artículo de El Popular de 2012), a la diversidad de etnias, pero unidas todas en una única «devoción». En este sentido, la lectura que se lleva a cabo en ambos diarios parece simplificar la dinámica misma de un evento especialmente rico de significaciones sociales para un grupo que parece no enfrentar ningún desafío a la hora de transmitir, en toda su riqueza y complejidad, una «tradición» que, en realidad, envuelve múltiples representaciones. En consecuencia, el cambio social y las resignificaciones son parte de las ausencias en los discursos periodísticos. Pareciera entonces que «lo boliviano» en Olavarría constituye un todo, un conjunto mayor, indeterminado, sin mayores distinciones internas, que conserva una identidad inmutable. Sin embargo a través del trabajo de campo etnográfico realizado con la comunidad (Mariano 2014), se constató que lejos de ser un grupo sin fisuras, presenta conflictos de intereses y divergencias entre generaciones respecto de los objetivos de la Asociación y los múltiples modos de manifestarse.

\section{El caso de Azul}

Desde el 2011, la comparsa Reina Mora comenzó a participar de los carnavales locales de Azul. El despliegue de color, el rico diseño de los trajes, las máscaras y el movimiento de sus danzas, no pasó inadvertido. Por el contrario, obtuvo por tres años consecutivos el primer premio que se otorga a la mejor comparsa, logrando, de este modo, el reconocimiento tan esperado. El primer paso estaba dado. Sin embargo, los alcances fueron más allá de lo previsto y se plasmaron en notas periodísticas que tomaron a Reina Mora como protagonista y a sus organizadoras como sus portavoces. De este modo, aquel barrio marginado comenzó a tener presencia en los medio de comunicación de la ciudad a través de la voz y la mirada de sus propios habitantes, y a ser protagonista de la vida cultural de una ciudad en donde «lo cultural» ocupa un 
lugar de privilegio en la agenda política y social, aunque no carece de cierta connotación elitista.

Cabe aclarar que la cantidad de notas existentes y relevadas para este caso en particular se corresponde con el reciente surgimiento de Reina Mora en el 2011, es por ello que no se encuentran publicaciones previas a ese año.

Una de las notas de prensa, extraída del diario Pregón de Azul de 2012, alude al trabajo y esfuerzo de padres y niños y a las metas alcanzadas. En términos del periodista: «los resultados son muy buenos y se ven a simple vista». Para argumentar esta idea, recoge el testimonio de una de sus fundadoras para quien «más allá de los premios, nuestra mayor alegría es ver a la gente entusiasmada y trabajando, y agrega, «mucha gente conoció el carnaval por nosotros, porque ellos no salían del barrio» (Pregón, enero de 2012).

Si bien en la publicación se describe la historia de la formación de la comparsa y se plantea cuáles fueron los objetivos iniciales, no se advierte una problematización con respecto a la existencia de un conjunto de ciudadanos «cautivos» de un barrio que antes no participaba ni conocía el evento popular y masivo del carnaval hasta que se conformó la comparsa. En las restantes notas relevadas tampoco se realiza un análisis que recupere el tema de la discriminación y se cuestionen temas como el rol del gobierno local y sus políticas de inclusión y participación.

En un blog que cuenta con un archivo de información y fotografías de acontecimientos realizados en Azul, denominado «El Quijote no se mancha» ${ }^{3}$, se encontró una noticia que, a diferencia de las otras, construye el relato a partir de imágenes correlativas que dan cuenta del proceso de formación de Reina Mora. Cada una de las fotografías que reproduce es acompañada de una frase que permite comprender la secuencia de los hechos. La primera, por ejemplo, tiene como protagonistas a jóvenes con tachos en las calles del barrio, lo que habría constituido el puntapié inicial para la conformación del grupo. La segunda, muestra a un conjunto de hombres y mujeres elaborando manualmente los trajes con los que irían luego a participar de la comparsa. Otra imagen reproduce finalmente su participación en el carnaval de Azul. El resto de las imágenes dan cuenta de los mensajes que desean transmitir, como por ejemplo, «no a la discriminación» como bandera central. Finalmente, señalan como epígrafe de una fotografía el modo en que «lograron integrarse y dejar de lado algunas enemistades barriales aportando a un proyecto colectivo». Si bien hay una clara participación de las responsables de la comparsa en la selección de las imágenes de esta nota, al menos se evidencia un compromiso del periodista por no dejar afuera estas cuestiones que los propios protagonistas perciben como cruciales.

El resto de las notas periodísticas (dos) retoman la «ardua labor» y el «trabajo» en la confección de máscaras «de varios tamaños y formas». Solamente una de ellas indaga acerca del significado de la danza, y transcribe textualmente el testimonio de una entrevistada: «Nosotros, con cada personaje que representamos, queremos transmitir algo, no es actuar por actuar. Queremos personificar el bien y el mal. Bailamos para Dios, para recibir su bendición, tal como ocurre en los carnavales de Oruro».

3 Esa denominación se vincula con el hecho de que Azul fue distinguida como Ciudad Cervantina de la Argentina por el Centro UNESCO Castilla-La Mancha en 2007, por poseer una de las colecciones privadas de El Quijote más importantes de América. En su conmemoración se realiza anualmente el Festival Cervantino. 
En esta misma nota, y en relación con todo lo expuesto, desde el área de Cultura del gobierno local se señala que «este año, como se viene trabajando, vamos por un carnaval en el que toda la familia disfrute de una fiesta popular, con paz y alegría, donde participen todos los barrios y todos sientan que tienen un lugar en esta fiesta que, cada año, busca ser más grande y de mayor calidad» (Pregón, enero de 2012).

Es significativo señalar cómo, a partir de entonces, comienza a aparecer en el discurso oficial esta idea de un lugar para «todos los barrios» en el carnaval. Reina Mora es una propuesta que surge desde los propios vecinos para disputar un escenario del cual antes no participaban ni se los convocaba para hacerlo. Una vez consolidado su espacio y visibilizada su agrupación por medio de un evento local y su repercusión en la prensa, esta comparsa es apropiada por el relato del gobierno municipal para argumentar el crecimiento y desarrollo de una «fiesta popular de paz y alegría».

A través de la búsqueda de otras noticias que aparecieran en los diarios de Azul, se identificó una que es interesante señalar. El 24 de abril de 2011, en la columna editorial del diario El Tiempo, se describe un encuentro provincial que se lleva a cabo anualmente para premiar y destacar a mujeres por su labor en pos del beneficio comunitario, teniendo en cuenta su aporte social a la comunidad e independientemente de su ideología política. Una de las ganadoras de este evento fue la «vecina azuleña Alfonsina» (una de las hermanas que organizó y creó Reina Mora) quien obtuvo como premio una beca para que finalizar los estudios secundarios, su asignatura pendiente. En la nota, se la describe como una mujer de 30 años, casada y con tres hijos y como una de las iniciadoras de la comparsa conocida como Reina Mora. En la misma se recupera también su testimonio en relación con el tema que la convirtió en la galardonada con este reconocimiento. Ella expresó que el hecho convocante fue siempre la comparsa, pero esto generó, a su vez, actividades paralelas de contención para niños y jóvenes. Señala: «por ejemplo, mientras estaban cosiendo los trajes con padres e hijos sabíamos de chicos que se habían llevado materias. Entonces usábamos ese tiempo reunidos para enseñarles algunas disciplinas escolares». Y finalmente manifestó, «esta es una demostración de que cuando se quiere, se puede. Solamente hay que encontrar el hecho motivador». La nota cierra afirmando que Alfonsina lo encontró y por eso ya han superado el centenar de niños y jóvenes que «en vez de andar por la calle» (El Tiempo, abril de 2011) se dedican a prepararse para actuar en la comparsa Reina Mora. Cabe destacar que este cierre del artículo se efectúa sin ninguna problematización ni análisis. Se presenta una imagen de los jóvenes estereotipada y sin matices, que se simplifica por su pertenencia a un barrio considerado marginal y los reduce a un espacio del cual deben ser rescatados.

\section{Manifestaciones bolivianas en la red social Facebook}

«Lo boliviano» en sus diversas manifestaciones, trasciende el ámbito geográfico en que se manifiesta y circula por otros espacios, como las redes sociales en Internet. Por ello, es interesante identificar cómo se activan estos otros lugares de producción de bienes simbólicos y culturales. De hecho, con su aparición, las redes virtuales han comenzado a ser parte fundamental de la interacción de personas y han comenzado 
a generar nuevas prácticas, lenguajes y modos de socialización, así como «nuevas formas de identificarse, representarse a sí mismos y ejercer su ciudadanía» (Aguilar Rodríguez y Said Hung 2010:192).

En los dos casos de análisis fue posible identificar la existencia de grupos en Facebook, una de las redes sociales gratuitas más utilizadas actualmente, con más de 900 millones de usuarios a nivel mundial. Estos grupos se constituyen como una vidriera a través de la cual pueden observarse determinadas imágenes que suelen diferir con las que circulan en el imaginario de la sociedad en general. Su elaboración puede ser entendida como una estrategia comunicacional que adquiere relevancia en la medida en que es construida por los propios protagonistas. Sin embargo, el desafío propio de la virtualidad torna, de alguna manera, difícil reconocer «la veracidad de las identidades creadas y ofrecidas por los sujetos en el ciberespacio», ya que ellos «dan la oportunidad a los individuos de crear versiones ideales de sí mismos» (Aguilar Rodríguez y Said Hung 2010:192). No obstante esas imágenes se construyen «desde adentro», es decir, a través de su propio relato y sin intermediarios y por ello, permiten conocer otra imagen de «lo boliviano».

En el caso de Azul, pudo encontrarse un grupo denominado de la misma forma que la comparsa antes presentada: Reina Mora. El grupo cuenta con 1248 amigos y 46 seguidores y a través de él es posible recuperar tanto la historia de su conformación como los modos en los que se definen. Por ejemplo, la información inicial consigna: «La comparsa Reina Mora fue creada por las mujeres de la familia Céspedes, hace 6 años y está conformada por chicos del barrio Pedro Burgos. Actualmente contamos con 115 integrantes». «Nuestra comparsa representa la cultura boliviana porque sus creadoras somos descendientes de ese país».

En dicho grupo puede advertirse cómo se adscriben a la condición de inmigrantes, siendo incluso la mayoría de ellas mujeres descendientes nacidas en Argentina. En una nota que publican en Facebook por el día de inmigrante, recuperan la definición del diccionario para luego discutirla e incorporarle lo que a ellas les parece que falta, a saber: «el término migración conlleva un cambio de residencia, bien sea temporario o definitivo (...) pero nunca refiere a los sentimientos, a los sueños ni a las esperanzas. No se habla de las barreras sociales ni de la discriminación, sólo de números»».

No obstante, los relatos en relación al modo de identificarse no terminan allí. Este espacio virtual es utilizado para expresar las percepciones de sí mismos y las que creen que «los otros» construyen acerca de ellos. Con la misma lógica, dedican una publicación para manifestar cómo los definen, para luego incluir aquello que no se dice: «muchos dicen que los bolivianos son buenos para trabajar en la construcción, sobre todo en los edificios, porque están acostumbrados a la altura. Pero nadie dice que estamos acostumbrados al esfuerzo, que nosotros llevamos grabada a fuego la cultura del trabajo».

Las referencias a un pasado, a una historia y un territorio (Bolivia), se plantean como las líneas que legitiman y delimitan al grupo, posibilitando la acumulación de un «capital inmaterial» $\mathrm{y}$, a su vez, una identificación colectiva en donde «ser trabajador» encuentra un lugar central. Su auto caracterización y heterodefinición como trabajadores los identifica como «un colectivo» diferente de otros grupos de inmigrantes, pero sin embargo, no define el contenido cultural que esta definición implica; 
es decir, no da cuenta por sí misma de lo que ello connota, que por supuesto va más allá de una cuestión innata o propia de un grupo.

En los relatos que las administradoras del grupo publican, pueden encontrarse también cuestiones propias de la identificación con una doble nacionalidad. Hay mensajes que dan cuenta de un sentimiento de pertenencia por el país que los recibió y los vio nacer: «con orgullo llevamos la bandera boliviana, pero nosotras sabemos que pertenecemos a este país».

Finalmente cabe mencionar que dicho grupo utiliza recursos visuales como fotografías con el fin de interpelar al observador/seguidor a través de imágenes que dan cuenta de procesos participativos, de solidaridad, de encuentro, de las tareas que se llevan a cabo en conjunto como la elaboración de trajes, máscaras y figuras decorativas.

A diferencia del caso de Azul, en Olavarría son las generaciones más jóvenes quienes comienzan a ocupar estos nuevos espacios virtuales, permitiéndoles otro tipo de visibilización y difusión por fuera del evento festivo que se lleva a cabo en torno a la Virgen de Copacabana. De hecho, el grupo que aparece en Facebook no representa la Asociación de Residentes Bolivianos de Olavarría sino a un grupo denominado «Caporales Sangre Morena», que invita a los jóvenes de entre 15 y 25 años a aprender la danza caporal. Es decir que su presencia en la red social incluye una variante particular del abanico de manifestaciones que representan a la colectividad como un grupo más amplio.

Allí se definen como un «Ballet artístico» que participa de diversos eventos, no sólo en Olavarría y en lo que ellos consideran «su cordón serrano», sino también en otras ciudades de la provincia de Buenos Aires, como Mar del Plata y Lobería. En dicho grupo, que actualmente cuenta con más de 3.470 amigos, queda registrada brevemente la historia de conformación del «Ballet», compuesto por más de 25 miembros y que, en sus palabras, «logra integrar a personas de diferentes edades, nacionalidades y barrios con el único fin de perfeccionar y difundir la danza Caporal $\rangle^{4}$.

A través de la visita a dicho grupo en Facebook es posible saber que: «el grupo inicialmente estaba constituido por seis bailarines que llevaban más de 15 años dedicándose a la danza del altiplano y que oficialmente el grupo se creó el 15 de abril de 2007».

Al igual que Reina Mora, recuperan significados y descripciones que consideran necesarios para poder entender en toda su dimensión y profundidad la danza caporal. Por ejemplo, desarrollan una explicación de los motivos que representan los nuevos trajes usados en las celebraciones: «Los trajes conjugan colores vivos, con un diseño innovador. Los lujosos apliques demuestran el poderío español a través de los escudos de armas. Las aves fénix, adornan sus trajes y buscan representar el mensaje de «resurgir de las cenizas».

Por último, y a diferencia nuevamente del caso anterior, la interpelación que se hace del seguidor es diferente. Si bien se usan imágenes coloridas con detalles de los

\footnotetext{
4 A través de este baile se representa una sátira a los capataces españoles, denominados «capos», quienes, en época de la colonia, hacían trabajar a los nativos del lugar en condiciones infrahumanas en las mitas y en el campo (Giorgis 2004). En este sentido, el Caporal sería la expresión corporal de la resistencia que se materializa en los primeros trajes de estos bailarines.
} 
trajes o de su participación en eventos, invitan a todos en general a sumarse al Ballet a través de frases como estas: «Si querés conocernos, bailar, ¡contratarnos! Comunicate», y agregan un teléfono. $\mathrm{O}$ «¿Te gustan las danzas bolivianas? ¡Te esperamos!» y luego ponen los días y la dirección para concurrir a los ensayos. $\mathrm{O}$ «Esta es la oportunidad, no te quedes afuera! Unite al Grupo caporales Sangre Morena!! Consultas por privado», entre otras.

En suma, las nuevas tecnologías de la información y la comunicación en el contexto global actual, les permite tender otro tipo de puentes con la comunidad. Las redes sociales, libres y gratuitas se convierten en herramientas disponibles. Se trata de un tipo de comunicación que, si bien no excluye a los mayores, es apropiado preferencialmente por las generaciones más jóvenes con el fin de crear un grupo que difunda y convoque a compartir y aprender acerca de la cultura boliviana. De este modo, se puede conocer la historia, los proyectos, los procesos de elaboración y consolidación, así como también el esfuerzo compartido por un conjunto de personas que desean visibilizar su cultura e identidad.

\section{Comentarios finales}

En este trabajo se partió del presupuesto de que cada grupo actualiza un corpus de referencia identitaria que no es homogéneo ni igualmente apropiado por todos sus miembros, y construye ámbitos de diferenciación social que pueden ser identificados a través del análisis de los medios de prensa (gráfica u online) y el uso de la red social Facebook. Esto posibilitó un abordaje original, de carácter preliminar, ya que no existen antecedentes de investigaciones sistemáticas en el área que analicen los procesos de identificación y las manifestaciones bolivianas desde estos espacios de comunicación.

Como pudo observarse, los periódicos tienen la capacidad de instalar temas en las agendas locales y dotarlos de relevancia aunque para ello suelan reconstruir narraciones a partir de la selección y la exclusión de determinados elementos socialmente significativos para el grupo en cuestión. En Azul y Olavarría, por ejemplo, la historia del barrio, las resistencias, las negociaciones y los desafíos para mantener una cultura boliviana al interior de una ciudad argentina, no se ponen de manifiesto. Incluso se observa que el desconocimiento del «otro» por parte del periodista que redacta la nota y que tiende siempre a simplificar el discurso. Las notas relevadas son de carácter descriptivo y en ellas se focaliza en cuestiones materiales y de impacto visual. Es recurrente el uso de frases que aluden al color, al brillo, a la alegría y al movimiento, pero no se ofrece ninguna explicación en relación con los sentidos que estos elementos implican, ni una problematización sobre los contextos, los conflictos y los valores que representan. Tampoco se hace referencia a otras cuestiones que aluden a símbolos o rituales nativos.

Pudieron observarse diferencias en cuanto al volumen (cantidad) de las publicaciones entre las dos ciudades. En Azul, su existencia es significativa sobre todo teniendo en cuenta que se trata de un movimiento que comenzó a emerger recién en los últimos años. El caso de Olavarría es el que presenta mayor cantidad de publicaciones perio- 
dísticas. Esto puede explicarse, entre otras cuestiones, por poseer una comunidad más consolidada y con más antigüedad y, a su vez, donde sus prácticas son socialmente más reconocidas.

Para el caso de las representaciones que se construyen desde Facebook la cuestión es diferente ya que, como lo expresa Aguilar Rodríguez y Said Hung (2010:193), «el desarrollo de nuevas herramientas de comunicación, a partir de la plataforma tecnológica ofrecida por la Internet, ha permitido desarrollar redes sociales virtuales, en las cuales los conceptos de identidad y subjetividad adquieren nuevos matices y manifestaciones». De hecho, estos espacios posibilitan instancias de comunicación desde donde se generan nuevos sistemas de significación.

En relación a ello, como se ha desarrollado previamente, existen agrupaciones que utilizan estos otros espacios y construyen grupos en los cuales no sólo comparten imágenes e información sino además visibilizan y promueven los eventos en los que participan. No obstante, no todos los grupos en Facebook se constituyen de la misma manera. Por ejemplo, en Olavarría el grupo se define a través de un cuerpo de danza en particular, y no en función de la Asociación o Centro en general. De este modo, estos grupos no estarían representando la totalidad sino un sector de la totalidad de manifestaciones bolivianas existentes a nivel local. En Azul, la comparsa Reina Mora se construye como un todo sin variables internas posibles de ser separadas.

En todos los casos presentados es posible observar cómo se construyen relatos a través de estrategias discursivas que ponen en marcha un juego de interacciones que permiten, a través de la virtualidad o la escritura (para el caso de la prensa) aportar interpretaciones cualitativas de procesos históricos-sociales en general, y de manifestaciones culturales en particular. Por ello, no puede dejar de reconocerse que tanto desde la prensa como desde la red social, se ponen de manifiesto procesos y estrategias de visibilización de «lo boliviano» desde una perspectiva subjetiva e incluso arbitraria. En ambos espacios hay una clara selección de elementos que le dan forma al discurso y que promueven una imagen específica. La diferencia central es que desde la prensa dicha representación es construida por actores externos al grupo (periodistas) mientras que en Facebook lo hacen los propios sujetos intervinientes (los inmigrantes bolivianos y sus descendientes). No obstante es necesario reconocer que en ambos casos lo que se pone en juego son modelo ideales construidos y redefinidos permanentemente.

Este análisis permiten reflexionar sobre las diversas estrategias de visibilización que se ponen de manifiesto en la prensa y en las redes sociales y, a su vez, cómo a partir de ellas se legitiman diversas imágenes y saberes, y se excluyen e invisibilizan otras. En ambas, la posibilidad de poner en juego la construcción y negociación de alteridades, no sólo ofrece la opción de que esta alteridad trascienda el lugar donde se manifiesta, sino que permite, además, identificar estos espacios como instrumentos que intervienen, de manera creciente, en la delimitación de espacios de poder y reconocimiento.

Si como lo expresa Grimson (2005: 43) «las identidades se construyen en relatos que establecen los límites entre un nosotros y un ellos», estos medios de comunicación se convierten en ámbitos privilegiados para analizar y comprender los procesos de interacción simbólica entre inmigrantes (y descendientes) con otros grupos so- 
ciales. Es decir, ponen en escena situaciones de «interculturalidad» en las que dos grupos que producen identificaciones y códigos comunicaciones diferentes, se relacionan y dialogan produciendo divergencias, negociaciones y discursos diversos.

En suma, los medios de comunicación y las «nuevas» tecnologías son entendidos como instrumentos y espacios propicios para la construcción, transformación y recreación de las identidades. A través del uso de ellas se construyen posicionamientos que buscan entender la cultura (en el caso de la prensa) y de visibilizar (para el caso de los inmigrantes y descendientes) otros relatos que no se asientan en discursos que promueven la desigualdad sino que establecen una comprensión que tiende a simetrizar las relaciones sociales (Grimson 2005). Así se genera una comunicación intercultural (Caggiano 2005) y se posibilita un espacio de relación que no es necesariamente un lugar físico real sino un territorio discursivo. En términos de Caggiano, estudiar la comunicación intercultural «significa investigar dispositivos de producción (y reproducción), más que espacios de encuentro» (2005:33); implica un juego de atribuciones y auto percepciones que es condición y resultado de los procesos de interlocución.

AGRADECIMiENTos: Este trabajo fue realizado en el marco de investigaciones desarrolladas por el Equipo Interdisciplinario de Estudios sobre el Patrimonio (PATRIMONIA), en el marco de INCUAPA (Unidad Ejecutora CONICET), de la Facultad de Ciencias Sociales, Universidad Nacional del Centro de la Provincia de Buenos Aires. Las investigaciones fueron financiado a través de los proyectos PICT 0561/11 de la ANPCyT y PIP 201101 00429-2012 CONICET, dirigidos por María Luz Endere.

\section{Referencias bibliográficas}

Aguilar Rodríguez, Daniel y Elías SAid Hung

2010 «Identidad y subjetividad en las redes sociales virtuales: caso de Facebook». Zona Próxima 12: 190-207.

BALAN, Jorge

1990 «La economía doméstica y las diferencias entre los sexos en las migraciones internacionales: un estudio sobre el caso de los bolivianos en la Argentina». Estudios Migratorios Latinoamericanos 35: 269-294.

BENENCIA, Roberto

1997 «De peones a patrones quinteros. Movilidad social de familias bolivianas en la periferia bonaerense». Estudios Migratorios Latinoamericanos 35 (12): 63-102.

2008 «Migrantes bolivianos en la periferia de ciudades argentina: procesos y mecanismos tendientes a la conformación de territorios productivos y mercados de trabajo», en Las migraciones en América Latina. Políticas, culturas y estrategias, Susana Novick, comp., pp. 13-30. Buenos Aires: Catálogos.

2009a «Inserción de bolivianos en el mercado de trabajo de la Argentina». Trabajo presentado en el Congreso 2009 de la Asociación de Estudios Latinoamericanos, 11 al 14 de junio de 2009. Río de Janeiro, Brasil.

2009b «Migraciones y derechos humanos. Legislación, agenda política y discursos mediáticos», en Temas de patrimonio cultural 24. Buenos Aires Boliviana. Migracio- 
nes, construcciones identitarias y memoria, Leticia Maronese, ed., pp. 309-313. Buenos Aires: Ministerio de Cultura.

BogGi, Silvia.

2011 «Identidades urbanas locales en Facebook. Reflexiones acerca del trabajo etnográfico en el ciberespacio», en Antropologia y crisis global: desafios para una interpretación desde el sur, Alicia Villafañe y Ludmila Adad, eds., pp. 305-312. Olavarría: Unicen.

Caggiano, Sergio

2005 Lo que no entra en el crisol. Inmigración boliviana, comunicación intercultural y procesos identitarios. Buenos Aires: Prometeo.

CONFOrTi, María Eugenia

2012 El rol de la comunicación pública de la arqueología y la educación no formal en la valoración social del patrimonio arqueológico en la provincia de Buenos Aires. Tesis de doctorado inédita. Bernal: Universidad Nacional de Quilmes.

Gavazzo, Natalia

2005 «El patrimonio cultural boliviano en Buenos Aires: usos de la cultura e integración», en Folklore en las grandes ciudades. Arte popular, identidad y cultura, Alicia Martín, ed., pp. 37-76. Buenos Aires: Libros del Zorzal.

GARCía VÁzQuez, Cristina

2005 Los migrantes. Otros entre nosotros. Etnografía de la población en la provincia de Mendoza. Mendoza: Universidad Nacional de Cuyo.

Giorgis, Marta

2004 La Virgen prestamista. La fiesta de la Virgen de Urkupiña en el boliviano Gran Córdoba. Buenos Aires: Antropofagia.

Grimson, Alejandro

1997 «Relatos de la diferencia y la igualdad. Los bolivianos en Buenos Aires». Nueva Sociedad 147: 96-107.

2000 «La migración boliviana en la Argentina. De la ciudadanía ausente a una mirada regional», en Cuadernos de Futuro 7: Migrantes bolivianos en la Argentina y los Estados Unidos, Alejandro Grimson y Edmundo Paz Soldán, eds., pp. 5-30. La Paz: Programa de Las Naciones Unidas para el Desarrollo.

2005 Relatos de la diferencia y la igualdad. Los bolivianos en Buenos Aires. Buenos Aires: EUDEBA.

LA Belle, Thomas

1980 Educación no formal y cambio social en América Latina. México: Nueva Imagen.

LAUMONIER, Isabel

1990 Festividad de Nuestra Señora de Copacabana. Buenos Aires: CEMLA.

LAUMONIER, Isabel, Manuel María Rocca y Eleonora SMOLEnsky

1983 Presencia de la tradición andina en Buenos Aires. Buenos Aires: Paidós.

LUdGER, Pries

2002 «Migración transnacional y la perforación de los contenedores de Estados nación». Estudios Demográficos y Urbanos 17 (3): 571-597.

Mccombs, Maxwell

2004 Setting the Agenda. The Mass Media and Public Opinion. Cambridge: Polity Press 
MARIANO, Mercedes

2011 «Patrimonio intangible e identidad: representaciones bolivianas en Olavarría, provincia de Buenos Aires, Argentina». Intersecciones en Antropología 12: 83-94.

2014 De representaciones, prácticas y fiestas bolivianas en las ciudades de Azul, Olavarría y Tandil, provincia de Buenos Aires. Un análisis desde la perspectiva del patrimonio cultural inmaterial. Tesis de doctorado inédita. Buenos Aires: Universidad de Buenos Aires, Facultad de Filosofía y Letras.

2015 «Acerca de la identidad boliviana en Argentina. Un análisis de tres casos de estudio en la provincia de Buenos Aires, Argentina». Antípoda: Revista de Antropología y Arqueología 22: 45-64.

SARRAMONA, Jaume

1992 La educación no formal. España: CEAC.

SASSONE, Susana

1994 «Los indocumentados y las amnistías migratorias», en Extranjeros en la Argentina. Pasado, presente y futuro, Graciela De Marco, Raúl Rey Balmaceda y Susana Sassone, eds., pp. 355-380. Buenos Aires: GEODEMOS.

2007 «Migración, religiosidad popular y cohesión social: bolivianos en el área metropolitana de Buenos Aires», en Diversidad cultural, creencias y espacios. Referencias empíricas, Cristina Carballo, ed., pp. 57-108. Luján: Universidad Nacional de Luján.

2009 «Breve geografía histórica de la migración boliviana en la Argentina», en Temas de Patrimonio Cultural, $\mathrm{n}^{\circ}$ 24, Leticia Maronese, ed., pp. 389-401. Ciudad de Buenos Aires: Ministerio de Cultura.

SASSONE, Susana y Graciela De MARCo

1991 Inmigración limitrofe en la Argentina. Buenos Aires: CEMLA - CCAM.

Rotman, Mónica

2004 «La creación urbana de tradiciones locales», en Antropología de la cultura y el patrimonio. Diversidad y desigualdad en los procesos contemporáneos, Mónica Rotman, ed., pp. 135-151. Buenos Aires: Ferreyra Editor.

VERON, Eliseo

1992 «Interfaces: sobre la democracia audiovisual avanzada», en El nuevo espacio público, Eliseo Verón, ed., pp. 124-139. Barcelona: Gedisa.

Zalles Cueto, Alberto

2002 «El enjambramiento cultural de los bolivianos en la Argentina». Nueva Sociedad 178: 89-103. 